\title{
Nanoscale Chemical Imaging of an Individual Catalyst Particle with Soft X-ray Ptychography
}

\author{
Anna M. Wise, ${ }^{\dagger}$ Johanna Nelson Weker, ${ }^{\dagger}$ Sam Kalirai, ${ }^{\S}$ Maryam Farmand, ${ }^{\ddagger}$ David A. Shapiro, ${ }^{\ddagger}$ \\ Florian Meirer, ${ }^{*}$, and Bert M. Weckhuysen*, ${ }^{*}$ \\ ${ }^{\dagger}$ Stanford Synchrotron Radiation Lightsource, Stanford University, Menlo Park, California 94025, United States \\ ${ }^{\S}$ Inorganic Chemistry and Catalysis group, Debye Institute for Nanomaterials Science, Utrecht University, 3584 CG Utrecht, The \\ Netherlands \\ ${ }^{\ddagger}$ Advanced Light Source, Lawrence Berkeley National Laboratory, Berkeley, California 94720, United States
}

\section{Supporting Information}

ABSTRACT: Understanding Fe deposition in fluid catalytic cracking (FCC) catalysis is critical for the mitigation of catalyst degradation. Here we employ soft X-ray ptychography to determine at the nanoscale the distribution and chemical state of $\mathrm{Fe}$ in an aged FCC catalyst particle. We show that both particle swelling due to colloidal $\mathrm{Fe}$ deposition and Fe penetration into the matrix as a result of precracking of large organic molecules occur. The application of ptychography allowed us to provide direct visual evidence for these two distinct Fe-based deactivation mechanisms, which have so far been proposed only on the basis of indirect evidence.

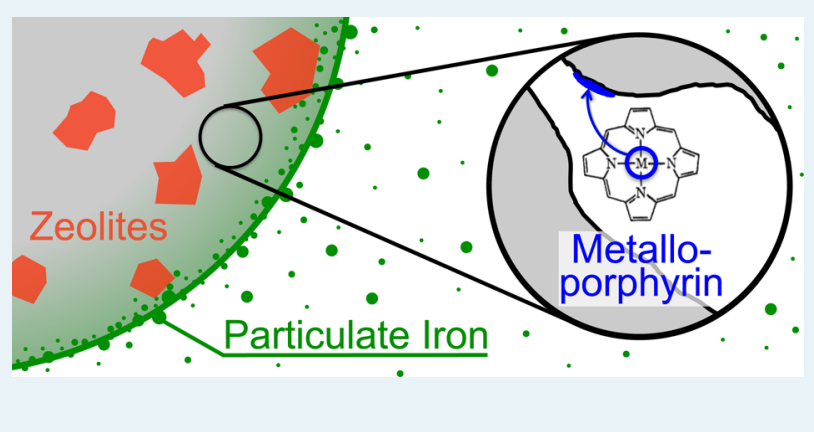

KEYWORDS: fluid catalytic cracking, chemical imaging, catalyst deactivation, iron and soft X-ray ptychography

$S_{\text {dit }}^{\text {of }}$ oft X-ray ptychography is a high-resolution coherent diffraction imaging technique ${ }^{1-3}$ with demonstrated resolutions of sub $5 \mathrm{~nm}$. When employed at a synchrotron, the tunable nature of synchrotron radiation means that the characteristic absorption edge energies of different elements can be used for $2 \mathrm{D}$ elemental mapping and for determining the chemical states of the elements by collecting pixel-by-pixel nearedge X-ray absorption fine structure (NEXAFS) data. Owing to the larger penetration depth of X-rays, thicker samples (up to a few microns) can be studied than possible with transmission electron microscopy.

Here we employ the unique power of soft X-ray ptychographic chemical imaging in order to characterize a hierarchically structured complex porous material as typically employed in heterogeneous catalysis. As a model material, we chose an individual, commercial equilibrium catalyst (ECAT) particle used in FCC. This material was selected because of its importance in catalysis-FCC particles are the workhorse of current oil refinery-and because understanding the transport of feedstock molecules through the pore space of these particles is essential for improving the efficiency of the cracking process and the lifetime of the catalyst. ${ }^{5-8}$

More specifically, it was shown that metal accumulation and deposition into the catalyst body can influence the product distribution and reduce catalytic activity by reducing bulk accessibility ${ }^{5,-13}$ and damaging the zeolite domains. ${ }^{14-16}$ The latter are embedded in the particle matrix and represent the catalytically most active phase of the catalyst. FCC catalyst particles are a compound material consisting of a macro- and meso-porous matrix (pores sizes above $50 \mathrm{~nm}$ and between 2 to $50 \mathrm{~nm}$, respectively ${ }^{17}$ ) mainly formed by clay and some additives, as well as embedded microporous zeolite crystallites (pore sizes below $2 \mathrm{~nm}^{17}$ ). ${ }^{18-20}$ The matrix plays an important role in the cracking of the heavy, long-chain feedstock molecules into product molecules like gasoline, because the large feedstock molecules cannot enter the micropores of the zeolite and therefore need to be precracked by the active part of the catalyst matrix. It was suggested that it is this precracking of metal carrying feedstock molecules like porphyrin, porphyrinlike complexes, or naphtenates that causes the deposition of $\mathrm{Ni}$ (mainly porphyrins ${ }^{21}$ ) and $\mathrm{Fe}$ (organic $\mathrm{Fe}$, naphtenates ${ }^{22}$ ) in the pore space of the catalyst. ${ }^{5,8,23,24}$ Previous 2D studies of individual FCC catalyst particle cross sections and recent 3D measurements of whole particles ${ }^{5,9-11}$ reported a $1-5 \mu \mathrm{m}$ thick surface layer of increased $\mathrm{Fe}^{13,22,25-27}$ and $\mathrm{Ni}^{23-25,28}$ concentrations for both industrially as well as lab-deactivated catalysts, suggesting low metal mobility after deposition. However, in the case of $\mathrm{Fe}$, a second deposition mechanism was suggested through deposition of colloidal $\mathrm{Fe}$ originating from the reactor hardware or soil contamination. This second mechanism was assumed to be mainly responsible for the formation of a nodulated particle surface as observed for FCC

Received: January 22, 2016

Revised: February 18, 2016

Published: February 26, 2016 
catalysts with high Fe concentrations, because the Fe particles are too large to enter the catalyst and are, therefore, deposited on the particle surface. Once deposited, $\mathrm{Fe}$ can cause a vitrification of the particle surface by lowering the melting point of the material. ${ }^{25}$

While previous spectroscopic and microscopic studies have provided valuable insight into the deposition of $\mathrm{Fe}$, 5,9,11,25-27 Fe speciation within an ECAT FCC catalyst has not yet been performed. The reason is that a technique is required that allows high-resolution chemical mapping of relatively low Fe concentrations in thick samples (several hundreds of nanometers, i.e. the typical size of zeolite domains) to maintain the structural integrity of the porous sample. Fe speciation is needed to fully understand the complex deposition mechanism of $\mathrm{Fe}$ in FCC particles. As discussed above, deposited $\mathrm{Fe}$ is known to block pores, thereby reducing catalyst activity, ${ }^{5}$ but $\mathrm{Fe}$ is also present in the matrix as a constituent of the kaolin clay. Spatially resolved NEXAFS is therefore needed to investigate whether the deposited $\mathrm{Fe}$ is in a different chemical state to the $\mathrm{Fe}$ in the matrix. Finally, high spatial resolution is required to identify if the $\mathrm{Fe}$ is present in nanoparticulate form, if it is present only at the surface, and if there is any morphological effect of $\mathrm{Fe}$ on the zeolite crystallites.

We therefore studied an individual FCC catalyst particle cross-section using chemical mapping with soft X-ray ptychography, to investigate the chemistry and deposition profile of Fe in an ECAT FCC catalyst. The catalyst was of the same type as the one we have studied in our previous work using lower-resolution X-ray nanotomography. ${ }^{11}$ Ptychography data were collected at beamline 5.3.2.1 of the Advanced Light Source, Lawrence Berkeley National Laboratory on a FCC particle cross section sliced to a thickness of $500 \mathrm{~nm}$. Scanning transmission X-ray microscopy (STXM) data were initially recorded at $700 \mathrm{eV}$ to identify a $7 \mu \mathrm{m} \times 7 \mu \mathrm{m}$ region of interest (ROI) for elemental mapping using ptychography. Ptychography data were also collected over a $3 \times 3 \mu \mathrm{m}$ field of view for NEXAFS analysis at the $\mathrm{Fe} \mathrm{L}_{3}$ edge. Figure 1 shows the identification of the ROIs with STXM $(A, B)$ and the higherresolution ptychography $(\mathrm{C}, \mathrm{D})$.

Ptychography data were collected over the same $7 \mu \mathrm{m} \times 7$ $\mu \mathrm{m}$ region (Figure $1 \mathrm{C}$ ) using $\mathrm{X}$-ray energies around the $\mathrm{Fe} \mathrm{L}_{3}$ edge (704, 708, and $710 \mathrm{eV}$ ) and the La $\mathrm{M}_{5}$ edge (830 and $834.5 \mathrm{eV}$ ) to create a map of $\mathrm{La}$ and Fe distributions in the particle as shown in Figure 2. Conservative estimates (determined as detailed in the Supporting Information) indicate that the ptychography images have resolutions of $12.2-14.2 \mathrm{~nm}$. La was used as a marker for the La-exchanged USY-zeolite crystallites, which can be seen distributed throughout the particle. $\mathrm{Fe}$ is present in low concentrations in the center of the particle as a constituent of the matrix (kaolin clay), whereas much higher concentrations of $\mathrm{Fe}$ are seen in the surface region of the particle, which is in agreement with our previous studies of ECAT particles. ${ }^{5,9-11}$

The capability to map both $\mathrm{Fe}$ and La distributions at the nanoscale allowed us to observe for the first time that the $\mathrm{Fe}$ enrichment around the edge of the particle is occurring in zones that actually contain La domains (Figure 2). This means that $\mathrm{Fe}$ is not only deposited on the surface, increasing the size of the particle ("particle swelling" by deposition of colloidal $\mathrm{Fe}^{5}$ ), but also clearly penetrates into the original particle matrix containing the zeolites. Using the distribution of $\mathrm{Fe}$ as a marker for the penetration of these large organic molecules, we see that most of the precracking occurs in the first $\sim 1 \mu \mathrm{m}$ of the surface
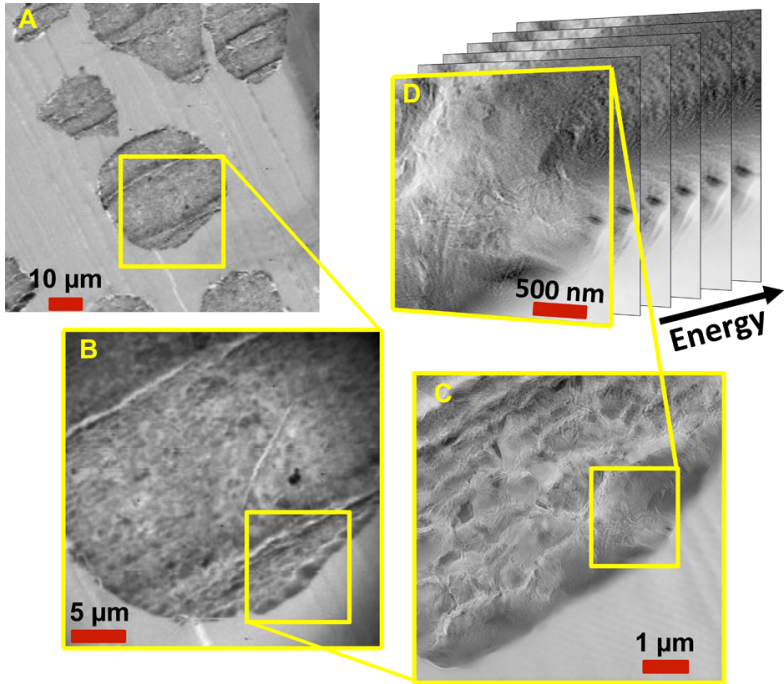

Figure 1. Scanning transmission $\mathrm{X}$-ray microscopy image of individual ECAT FCC particle cross sections (A,B), recorded at $700 \mathrm{eV}$, showing the region of interest selected for ptychography. Ptychography data were collected over the region shown in (C) for elemental mapping of $\mathrm{Fe}$ and La. The ROI was reduced to the region shown in (D) for NEXAFS analysis, recording a series of images across the $\mathrm{Fe} \mathrm{L}_{3} \mathrm{X}$-ray absorption edge. All data were collected using a beam footprint of 100 $\mathrm{nm}$ on the sample.
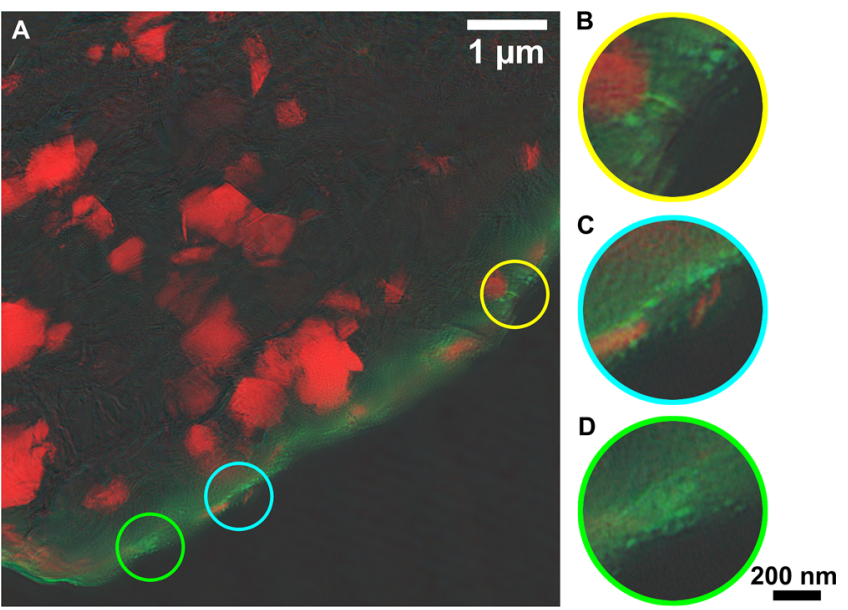

Figure 2. (A) Distribution of La (red) and Fe (green) within the ECAT FCC particle derived from ptychography data collected at the $\mathrm{Fe} \mathrm{L}_{3}$ and $\mathrm{La} \mathrm{M}_{5}$ absorption edges. Circles highlight particulate $\mathrm{Fe}$ visible at the surface of the particle. $(B-D)$ Enlarged view on the corresponding encircled areas.

of the FCC particle. This shows that the permeability for such large molecules is small, likely due to the higher density of the particle crust limiting accessibility for these molecules. Furthermore, as a result of the high spatial resolution of the data, evidence for particulate $\mathrm{Fe}$ can be seen in the very surface of the particle, highlighted by the zoomed areas in Figure 2 (and Figure S2). These observations provide the first clear evidence for both proposed Fe deposition mechanisms, namely, deposition of inorganic particulate Fe known as "tramp Fe", "colloidal $\mathrm{Fe}$ ", or "fine dust $\mathrm{Fe}$ ", and accumulation of $\mathrm{Fe}$ through the precracking of large $\mathrm{Fe}$ transporting porphyrin and/or naphthenate molecules in the matrix. As shown in our previous work, this deposition of $\mathrm{Fe}$ at and near the surface leads to the reduction in catalyst activity due to pore clogging. 
Previous reports have observed vitrification as a result of $\mathrm{Fe}$ contamination especially in combination with $\mathrm{Ca}$ or $\mathrm{Na}^{25,26,29}$ In our previous work, we have confirmed the correlation of $\mathrm{Fe}$ and Ca particularly at the surface in these ECAT particles using lower-resolution XRF tomography. ${ }^{9}$ While vitrification is not directly observed here, the change in texture visible in the regions where particulate $\mathrm{Fe}$ is seen, along with the overall degree of $\mathrm{Fe}$ contamination, suggests that vitrification of the surface is likely to have occurred, thus supporting the theory that $\mathrm{Fe}$ and $\mathrm{Ca}$ can lower the melting point of the matrix resulting in significant pore blocking due to vitrificaton.

The distribution map of $\mathrm{La}$ and Fe (Figure 2) was further analyzed to estimate the particle size distribution of zeolites as shown in Figure 3 (details provided in the Supporting

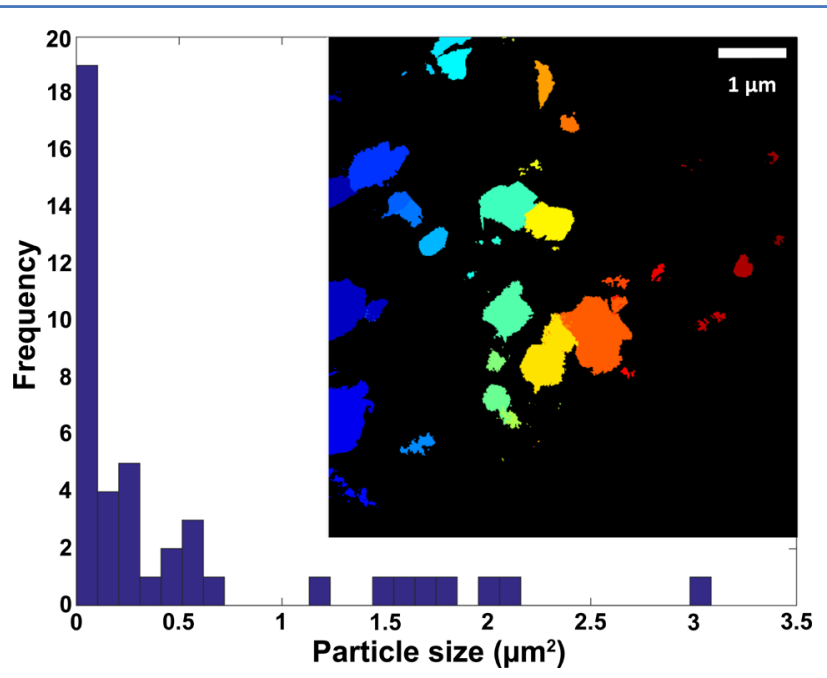

Figure 3. Particle size distribution of the La-containing zeolite domains. Discrete particles are indicated by different colors (inset) for the La particles seen in red in Figure 2.

Information). The particle sizes obtained from this analysis vary from 0.1 to $3 \mu \mathrm{m}^{2}$. Owing to the high resolution of these ptychographic images, it can be seen that some zeolite domains are conjoined-a detail which would be lost with lower resolution imaging methods and which paves the way for detailed analysis of the degradation of the zeolite domains themselves. It further confirms that a sample preparation resulting in thicker cross sections is preferred to minimize damage to zeolite crystallites.

To investigate the chemical state of $\mathrm{Fe}$ within the particle, ptychography images of a $3 \mu \mathrm{m} \times 3 \mu \mathrm{m}$ area were collected at 41 energies over the $\mathrm{Fe}_{3}$ absorption edge $(700-720.5 \mathrm{eV})$ to generate per pixel NEXAFS data. Principle component analysis (PCA) and subsequent clustering (see SI) were used to define the distribution of different Fe chemical states without using $a$ priori knowledge about the $\mathrm{Fe}$ phases that are present (Figure 4). The resulting image segmentation clearly shows that the $\mathrm{Fe}$ phase correlates with $\mathrm{Fe}$ concentration and that the surfacedeposited $\mathrm{Fe}$ is of a different phase than the $\mathrm{Fe}$ in deeper regions (i.e., in the matrix).

Based on the inspection of the average NEXAFS of each cluster (Figure 4C), the distribution of the Fe phases shows a more reduced state in the matrix (dark and light blue) and a sandwich structure of more oxidized states in the surface layer (following the order from green to purple to yellow). Here it is interesting to point out what seems to be a crack in the surface
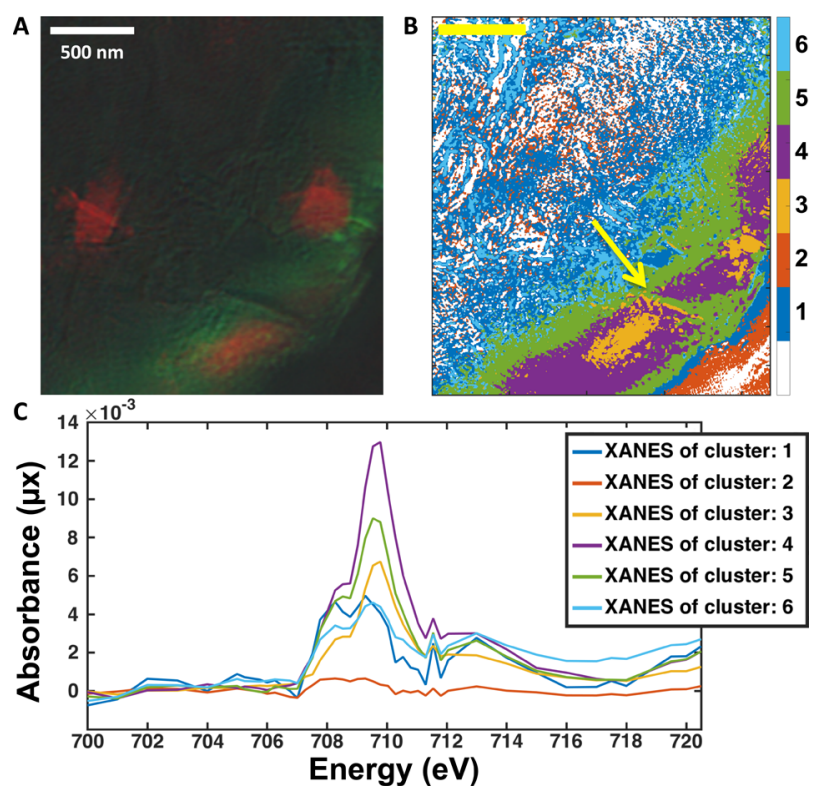

Figure 4. La (red) and Fe (green) distribution map (A) and cluster map (B) generated from principal component analysis and clustering of the per pixel NEXAFS data. In (C), the average NEXAFS of each generated cluster are reported showing clear differences in $\mathrm{Fe}$ phase. The arrow in (B) highlights the crack visible in the surface layer.

layer (indicated by the arrow in Figure 4B) that interrupts this sandwich structure of the Fe phase distribution, which could relate to a reduction process occurring following deposition. Such a postdeposition reduction would also explain the layer of more reduced $\mathrm{Fe}$ at the very surface of the particle. Finally, as shown in Figure 4A,B, zeolite domains are present very near to the surface of the particle, which seem to hinder Fe transport into the particle and cause $\mathrm{Fe}$ to accumulate on the surface.

In addition to PCA, linear combination fitting (LCF) was carried out to determine the oxidation state of the $\mathrm{Fe}$ species present in the sample. $\mathrm{FeO}\left(\mathrm{Fe}^{2+}\right)$ and $\mathrm{Fe}_{2} \mathrm{O}_{3}\left(\mathrm{Fe}^{3+}\right)$ reference spectra were used as standards for the fitting, with the resulting intensity and distribution maps of the different oxidation states shown in Figure 5. ${ }^{30} \mathrm{~A}$ clear separation is seen between the chemistries of the Fe present in the original matrix and the $\mathrm{Fe}$ deposited at the surface. Previous studies have used XPS or electron diffraction to identify the iron species present at the surface as $\mathrm{Fe}_{2} \mathrm{O}_{3}$, in agreement with our analysis. ${ }^{27}$ However, this is the first time it has been possible to map and discriminate the Fe chemical state both at the surface and in the body of the particle. The intensity of the signal suggests that the $\mathrm{Fe}$ concentration at the surface is at least $5 \times$ greater than in the catalyst particle body. Previously, it was shown that the mobility of $\mathrm{Fe}^{2+}$ in feldspars (other aluminosilicates) can be $10 \times$ higher than that of $\mathrm{Fe}^{3+31}$ This suggests that the accumulation of $\mathrm{Fe}$ at the surface is related to the chemical nature of $\mathrm{Fe}$ that is deposited. Once accumulated and immobile, particle swelling effects are exacerbated and catalyst accessibility is lowered further. Enhanced concentrations of $\mathrm{Fe}$ at the surface have also been attributed to agglutination of FCC particles resulting in further detrimental effects on catalyst performance during operation. ${ }^{10}$

Using soft X-ray ptychography, we found direct evidence that $\mathrm{Fe}$ deposition is occurring as a result of both "tramp" Fe and due to precracking of large, iron-carrying organic molecules, with the deposited iron in a different chemical state (i.e., $\mathrm{Fe}^{3+}$ ) 

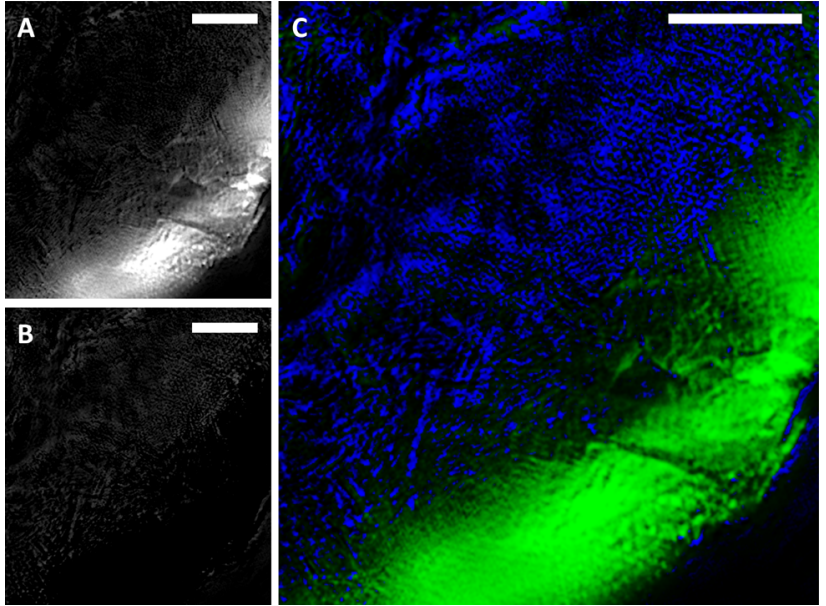

Figure 5. Intensity maps of $\mathrm{Fe}^{3+}(\mathrm{A})$ and $\mathrm{Fe}^{2+}(\mathrm{B})$ determined by LCF of the per-pixel NEXAFS data. Intensity maps were rescaled and combined to map the relative distributions of $\mathrm{Fe}^{3+}$ (green) and $\mathrm{Fe}^{2+}$ (blue) (C). NEXAFS spectra and a map of $R^{2}$ values are shown in the Supporting Information (Figures S9 and S10).

than the iron present in the matrix (i.e., $\mathrm{Fe}^{2+}$ ). The high resolution attainable with ptychography combined with the large field of view and relatively thick sample has enabled the detailed analysis of the nature of Fe poisoning in an industrial FCC catalyst particle that is not obtainable with other techniques.

\section{ASSOCIATED CONTENT}

\section{S Supporting Information}

The Supporting Information is available free of charge on the ACS Publications website at DOI: 10.1021/acscatal.6b00221.

Experimental details, detailed description of image processing, resolution analysis, domain size analysis, principle component analysis, and linear combination fitting (PDF)

\section{AUTHOR INFORMATION}

\section{Corresponding Authors}

*E-mail: f.meirer@uu.nl.

*E-mail: b.m.weckhuysen@uu.nl.

\section{Notes}

The authors declare no competing financial interest.

\section{ACKNOWLEDGMENTS}

This work was supported by the European Research Council (ERC) Advanced Grant (no. 321140) and by the Department of Energy, Laboratory Directed Research and Development funding, under contract DE-AC02-76SF00515. The Advanced Light Source is supported by the Director, Office of Science, Office of Basic Energy Sciences, of the U.S. Department of Energy under Contract No. DE-AC02-05CH11231. This work is partially supported by the Center for Applied Mathematics for Energy Research Applications (CAMERA), which is a partnership between Basic Energy Sciences (BES) and Advanced Scientific Computing Research (ASRC) at the U.S. Department of Energy.

\section{REFERENCES}

(1) Thibault, P.; Dierolf, M.; Menzel, A.; Bunk, O.; David, C.; Pfeiffer, F. Science 2008, 321, 379-382.
(2) Rodenburg, J. M.; Hurst, A. C.; Cullis, A. G.; Dobson, B. R.; Pfeiffer, F.; Bunk, O.; David, C.; Jefimovs, K.; Johnson, I. Phys. Rev. Lett. 2007, 98, 034801.

(3) Thibault, P.; Guizar-Sicairos, M.; Menzel, A. J. Synchrotron Radiat. 2014, 21, 1011-1018.

(4) Shapiro, D. A.; Yu, Y.-S.; Tyliszczak, T.; Cabana, J.; Celestre, R.; Chao, W.; Kaznatcheev, K.; Kilcoyne, A. L. D.; Maia, F.; Marchesini, S.; Meng, Y. S.; Warwick, T.; Yang, L. L.; Padmore, H. A. Nat. Photonics 2014, 8, 765-769.

(5) Meirer, F.; Kalirai, S.; Morris, D.; Soparawalla, S.; Liu, Y.; Mesu, G.; Andrews, J. C.; Weckhuysen, B. M. Sci. Adv. 2015, 1, e1400199.

(6) Cerqueira, H. S.; Caeiro, G.; Costa, L.; Ramôa Ribeiro, F. J. Mol. Catal. A: Chem. 2008, 292, 1-13.

(7) Vogt, E. T. C.; Weckhuysen, B. M. Chem. Soc. Rev. 2015, 44, $7342-7370$.

(8) Perego, C.; Millini, R. Chem. Soc. Rev. 2013, 42, 3956-3976.

(9) Kalirai, S.; Boesenberg, U.; Falkenberg, G.; Meirer, F.; Weckhuysen, B. M. ChemCatChem 2015, 7, 3674-3682.

(10) Meirer, F.; Kalirai, S.; Nelson Weker, J.; Liu, Y.; Andrews, J. C.; Weckhuysen, B. M. Chem. Commun. 2015, 51, 8097-8100.

(11) Meirer, F.; Morris, D. T.; Kalirai, S.; Liu, Y.; Andrews, J. C.; Weckhuysen, B. M. J. Am. Chem. Soc. 2015, 137, 102-105.

(12) Rainer, D. R.; Rautiainen, E.; Imhof, P. Appl. Catal., A 2003, 249, 69-80.

(13) Psarras, A. C.; Iliopoulou, E. F.; Nalbandian, L.; Lappas, A. A.; Pouwels, C. Catal. Today 2007, 127, 44-53.

(14) Pompe, R.; Jaras, S.; Vannerberg, N. G. Appl. Catal. 1984, 13, 171-179.

(15) Tangstad, E.; Andersen, A.; Myhrvold, E. M.; Myrstad, T. Appl. Catal., A 2008, 346, 194-199.

(16) Chao, K. J.; Lin, L. H.; Ling, Y. C.; Hwang, J. F.; Hou, L. Y. Appl. Catal., A 1995, 121, 217-229.

(17) Rouquerol, J.; Avnir, D.; Fairbridge, C. W.; Everett, D. H.; Haynes, J. H.; Pernicone, N.; Ramsay, J. D. F.; Sing, K. S. W.; Unger, K. K. Pure Appl. Chem. 1994, 66, 1739-1758.

(18) Scherzer, J. Appl. Catal. 1991, 75, 1-32.

(19) Chen, Y.-M. In Handbook of Fluidization and Fluid-Particle Systems; Yang, W.-C., Ed.; Marcel Dekker: New York, 2003; p 379.

(20) Sadeghbeigi, R. In Fluid Catalytic Cracking Handbook, 3rd ed.; Sadeghbeigi, R, Ed.; Butterworth-Heinemann: Oxford, 2012; p 87.

(21) Reynolds, J. G. Pet. Sci. Technol. 2001, 19, 979-1007.

(22) Yuxia, Z.; Quansheng, D.; Wei, L.; Liwen, T.; Jun, L. Stud. Surf. Sci. Catal. 2007, 166, 201-212.

(23) Kugler, E. L.; Leta, D. P. J. Catal. 1988, 109, 387-395.

(24) Lappas, A. A.; Nalbandian, L.; Iatridis, D. K.; Voutetakis, S. S.; Vasalos, I. A. Catal. Today 2001, 65, 233-240.

(25) Yaluris, G.; Cheng, W. C.; Peters, M.; McDowell, L. T.; Hunt, L. Stud. Surf. Sci. Catal. 2004, 149, 139-163.

(26) Wieland, W. S.; Chung, D. Hydrocarbon Eng. 2002, 7, 55-65.

(27) Bayraktar, O.; Kugler, E. L. Catal. Lett. 2003, 90, 155-160.

(28) Peters, A. W. Stud. Surf. Sci. Catal. 1993, 76, 183-221.

(29) Mathieu, Y.; Corma, A.; Echard, M.; Bories, M. Appl. Catal., A 2014, 469, 451-465.

(30) Regan, T. J.; Ohldag, H.; Stamm, C.; Nolting, F.; Lüning, J.; Stöhr, J.; White, R. L. Phys. Rev. B: Condens. Matter Mater. Phys. 2001, $64,214422$.

(31) Behrens, H.; Johannes, W.; Schmalzried, H. Phys. Chem. Miner. 1990, 17, 62-78. 